\title{
9
}

\section{A Transformative Model for Designing Professional Development Activities}

\section{David Langley}

Indiana State University

Terence W. O'Connor

The College of New Jersey

\section{Michele M. Welkener}

Indiana State University

A new model for professional and organizational development is presented based on concepts derived from Wilber (2000) and Astin (2001). The model consists of an individualpublic dimension and a reflection/performance dimension. Four quadrants that result from connecting these dimensions are formed: 1) individual reflection, 2) public reflection, 3) individual performance, and 4) public performance. We believe this model offers faculty developers a framework for designing thoughtful programs to aid faculty in meeting the wide range of internal and external demands that confrom bigher education institutions.

7 he purpose of this chapter is to present a comprehensive model for pro1 fessional development based on concepts underlying transformational change for institutions of higher education (Astin, 2001; Wilber, 2000). We view the model as one vehicle to resolve the tensions created when faculty attempt to align their beliefs and skills with changing institutional expectations. In particular, the model provides a framework for the ongoing development of professional skills to help the faculty member adapt to these expectations. 
The chapter is divided into five sections. First, we briefly outline our perspective on the nature of professional development for faculty. Next, the model is presented and connected to our emerging perspective. The third section lists the guiding assumptions or principles that have informed our development of the model. In the fourth section, we describe the opportunities and challenges that arise for faculty developers who wish to frame their programs based on the model. Finally, we conclude by providing a defensible warrant for exploring the model as scaffolding for professional and organizational development.

\section{Perspective on Professional Development}

The driving forces affecting today's universities are pressuring institutions to make fundamental changes in the traditional assumptions that guide faculty in their workday. For example, new faculty are assumed to be (or rapidly become) competent in the use of information technologies in their teaching (Farquhar, 2001). A more diverse group of students entering college (Swail, 2002) and an increased emphasis on globalization in undergraduate education (Green, 2002) have stretched faculty to adopt appropriate pedagogies to meet these demands. The market-oriented system of higher education, a growing list of for-profit higher education companies (Newman \& Couturier, 2001), and the ever-present fiscal pressures on higher education institutions (Lovett, 2002) eventually find their way into the academic lives of faculty. As a consequence of these forces, institutions have stressed the necessity of ongoing faculty renewal to cope with these changes (Farquhar, 2001)-a process that Cranton (1996) has termed transformative professional development.

We believe that the role of professional development involves guiding individuals as they negotiate the challenges described above. Because the relationship between a faculty member and an institution is complex and dynamic, the role of professional development in mediating this relationship cannot be simplistically designed. For example, faculty bring many personal elements to their work at the institution-expectations, motivations, assumptions, and knowledge. If these clements were preciscly aligned with the demands of the institution, then professional development would be unnecessary. In the changing environment of higher education, however, these institutional demands require flexible, adaptable faculty who are capable of revising their expectations and assumptions-that is, faculty who are willing to engage in transformative learning (Cranton, 1994, 1996; Mczirow, 1991, 2000). 
From an organizational development perspective, a university that acknowledges and supports the continuous renewal of faculty recognizes that this transformative learning is the basis for becoming a learning organization (Senge, 1990). Rather than a provider or transmitter of information, a professional development program in a learning organization is defined by its ability to help individuals respond effectively to the ongoing changes of the institution. This approach must go well beyond occasional workshops and reflection activities. What follows is a framework that outlines the key requirements of a systemic approach to professional development.

\section{The Four Quadrant Model for Professional Development}

Our model for professional development is designed to accommodate not only inevitable institutional changes but faculty adaptations to those changes. Table 9.1 outlines the essence of the model being proposed.

TABLE 9.1

The Four Quadrant Model for Professional Development

\begin{tabular}{|c|c|c|}
\hline & Reflection & Performance \\
\hline Individual & $\begin{array}{l}\text { Critical examination of professional } \\
\text { issues based on a personal } \\
\text { perspective. } \\
\text { Examples: } \\
\text { - Reading professional literature on } \\
\text { portfolio development } \\
\text { - Reading about the steps to } \\
\text { successful grant writing } \\
\text { - Reflecting on alternative classroom } \\
\text { pedagogies }\end{array}$ & $\begin{array}{l}\text { Observable professional or technical } \\
\text { skills necessary for achieving scholarly } \\
\text { outcomes. } \\
\text { Examples: } \\
\text { - Learning how to use Microsoft Office } \\
\text { - Acquiring competence in mulrivariare } \\
\text { statistical analysis } \\
\text { - Developing more advanced skills in } \\
\text { creative arts performances (music, } \\
\text { theater, art) }\end{array}$ \\
\hline Public & $\begin{array}{l}\text { Critical examination of professional } \\
\text { issues based on collaborative input. } \\
\text { Examples: } \\
\text { - Participating as a team member in } \\
\text { revising curricula } \\
\text { - Having a dossier reviewed by } \\
\text { colleagues prior to submission } \\
\text { - Discussing the merits of a new } \\
\text { teaching approach with a } \\
\text { collcague }\end{array}$ & $\begin{array}{l}\text { Scholarly outcomes observable to the } \\
\text { professional community. } \\
\text { Examples: } \\
\text { - Presenting a paper at a conference } \\
\text { - Presenting a crearive work at an } \\
\text { exhibition } \\
\text { - Publishing an article in a refereed } \\
\text { journal }\end{array}$ \\
\hline
\end{tabular}


We propose that professional development activities can be classified into two dimensions: individual/public and refection/performance. Four quadrants that result from connecting these dimensions are formed: 1) individual reflection, 2) public reflection, 3) individual performance, and 4) public performance. The dimensions and related quadrants flow from similar constructs identified by Wilber (2000) and Astin (2001). Wilber's terms (individual/collective and interior/exterior) are the genesis for our adaptations to his model for the professional development setting.

Our primary thesis is that these four quadrants represent components that need to be examined and addressed to support the growth of faculty. Each quadrant contributes to the overall capabilities of faculty in their work. In addition, the model challenges program directors to consider how both dimensions could be addressed in a comprehensive approach to enhance the professional capabilities of all faculty.

\section{The Individual/Public Dimension}

A professional development program that facilitates the relationship between a faculty member's personal orientation and the changing demands of the institurion must acknowledge the individual/public dimension. The individual component is comprised of those feelings and beliefs that articulate a faculty member's identity, sense of accomplishment, and satisfaction; it is the source of commitment and morale. This component also comprises the array of knowledge and skills that every faculty member brings to any performance demand.

The public component is one in which roles, duties, shared agreements, and standards are created and observed. Most notably, it defines the terms of institutional engagement that produce required outcomes, leading to the organization's success. The first demand of professional development, therefore, is to assist faculty members as they understand the changing individual/public tension and negotiate an acceptable fit within this dynamic relationship.

\section{The Reflection/Performance Dimension}

Institutional driving forces often present deep challenges to a faculty member's vision and commitment. These challenges implicate the need for reflection/performance, the second important dimension for professional developers to consider.

Reflection requires an individual to examine personal assumptions and is vital to the re-construction of prior beliefs. In addition, dialogue is a public form of reflection that allows dependable public agreements to emerge. Reflections 
must be balanced, however, by observable performance. Individuals must possess knowledge and skills that allow them to accomplish professional goals. In addition, higher education institutions have implicit and explicit standards to gauge faculty productivity. Public, summative assessments of performance are, in fact, the primary focus of review for evaluating faculty performance, while reflection tends to be viewed as a process that lies outside of traditional evaluation approaches.

To reprise, the relationship between faculty members and institutions appears to be reconstructed along four components: individual reflection, public reflection, individual performance, and public performance. The manner in which professional activities are woven together into a program should be based on a needs analysis that specifically identifies issues in each of these four components. What individ:al assumptions, left unchanged, will hinder this project? What public reflections must be shared and agreed upon through dialogue with the university community? What individual performance skills and knowledge are required for success? What performance outcomes and evaluations will be used to publicly validate that success? From our perspective, these questions highlight the major issues that must be addressed in selecting appropriate activities for faculty renewal.

A traditional program might focus on the public performance quadrant and limit professional development activities to providing information regarding technical aspects of work responsibilities. We assert that a comprehensive program for professional development can be designed around activities that deliberately address all four areas of professional competence. Conversely, failure to develop effective programs may be linked to a lack of addressing one or more of these areas.

\section{Guiding Assumptions of The Model}

Guiding assumptions underlying the model simplify and redirect the work of philosopher Ken Wilber (2000) toward a professional development setting. Wilber generated the model after an exhaustive search of common elements in hierarchical organizational structures found in a varicty of disciplines. The "four corners of the universe" (p. 139) emerged as a product of categorizing these hierarchies. Adaptations of Wilber's model have been used as organizational frameworks in school curriculum design, political science, business management, nutrition education, and prison education (Wilber, 2000).

Four assumptions emerge from our integrative approach: 
1) It follows that professional development activities are more comprehensively addressed - and may be more successful—when each quadrant exerts an appropriate impact on those activities.

2) While each quadrant can be viewed as an outcome (e.g., gaining personal insight into an issue could be a product in the individual reflection quadrant), the most valued outcome for many universities is likely to be the public performance quadrant. From a political perspective, professional developers may present the remaining three quadrants (individual reflection, individual performance, public reflection) as processes by which a super-ordinate goal can be achieved in the public performance quadrant.

3) Faculty may approach any professional development activity by more deeply exploring the relationship between the activity and each quadrant. For example, learning online course technology may involve increasing individual performance skills to use a software program in meeting the larger goal of developing an online course. At the same time, improving personal capacities for critical examination (individual reflection) is necessary to help the faculty member design a more appropriate course based on learning-centered principles.

4) The model can be applied to any of the traditional spheres of professional development, including teaching, research/creative activity, servicc/outreach, and professional and technical competencies.

\section{Applying the Model in a Professional Development Program: Opportunities and Challenges}

The model suggests a set of expected outcomes for faculty as they travel down a career path. Using language consistent with the model, we suggest that a faculty member who is functioning at a high level 1) demonstrates an ongoing capability to critically examine actions and beliefs (individual reflection), 2) actively engages in collegial discourse to meet professional obligations in the university and external community (public reflection), 3) has developed appropriate professional and technical skills to meet responsibilities in teaching, research, and service (individual performance), and 4) produces a valued set of scholarly outcomes that are observable to the university community (public performance). This vision for a more complete scholar should drive the design of a program to accommodate faculty growth across any carcer stage. What 
opportunities are present in a professional development program to exploit the characteristics of the model?

\section{Opportunities}

Two applications of the model are listed below. These examples illustrate how the model can be used as a faculty development tool on an individual and program level.

1) Individual consultations with faculty regarding the resolution of particular teaching concerns can profit from the model's approach. Consider a faculty member who is interested in developing an appropriate pedagogical approach for an upcoming course with a large enrollment. To successfully achieve this goal, four questions compatible with the model can be posed during a consultation: 1) What kinds of materials will you need to read or what issues do you need to consider in preparing to work on your task (individual reflection)? 2) What conversations will you need to have (and with whom) in order to get another perspective or feedback on your task (public reflection)? 3) What professional or technical skills do you need to have or develop to successfully complete the task (individual performance)? 4) What should be the expected outcome (product) and what timeline is necessary to be successful (public performance)?

2) Workshops that focus on developing faculty competencies in specific curricular tasks can benefit from framing the task within the model. For example, faculty who are learning how to develop a course syllabus can be expected to 1) critically reflect on the type of student learning desired in the course (individual reflection), 2) gain and use feedback from workshop parricipants about the proposed syllabus (public reflection), 3) assemble a set of materials and produce/format the written text (individual performance), and 4) produce the completed syllabus and defend its development on the first day of class to students (public performance).

\section{Challenges}

We continue to reexamine our assumptions about the model and how it may best serve the field of faculty development. We have been challenged by a host of issues that require resolution and outline three of these issues below.

1) It is apparent that the faculty designer may emphasize certain quadrants based on the nature of the task. For example, imagine a new faculty member who has a professional development plan that focuses on learning to enhance quantitative statistical competencies in data analysis. This 
goal primarily emphasizes individual performance skills and could be viewed as a necessary means to achieve a more efficient method of analyzing research data to increase publication productivity (public performance). The role of reflection may not be as strong in this task, although it is unlikely that it could be eliminated. This example does not invalidate the model but reminds faculty developers to avoid the assumption of equal emphasis (time, effort, focus) for every quadrant.

2) The order of addressing each of the quadrants in completing a professional development activity is not straightforward. Given a situation in which public performance is considered the end product, it seems likely that individual differences will arise regarding preferences for sequencing the remaining three processes. Should a faculty member initiate efforts on completing the task through individual reflection, or should collaborative input (public reflection) take precedence? Are there individual performance skills that need to be shored up prior to the reflective process? Are there tasks for which "preferred pathways" or sequences exist for every faculty member? These empirical questions require the weight of systematic data collection for resolution.

3) Wilber's (2000) model described developmental steps for each quadrant in such a way that each succeeding step transcends but includes its predecessors. Connections across equivalent levels in the quadrants were also labeled. A logical extension of Wilber's model for our purposes would suggest that faculty will experience phases in their growth in each quadrant. A clear description of these phases would enhance our understanding of adult development. This level of sophistication exceeds our current use of the model in a professional development setting but challenges us to examine how we may gain from more deeply exploring the approach adopted by Wilber.

\section{Conclusion}

We have recently tested the model in a university-wide curriculum seminar at Indiana State University and have emerged with a growing respect for the magnitude of faculty development issues that can be accommodated by the model. The model's apparent simplicity-two dimensions that define four quadrants-belies the complexity of development found in Wilber's (2000) approach with similar constructs. Nevertheless, testing the limits and benefits of the model seems warranted because the model takes into account both the formative nature of development (reflective processes) and the necessary 
products or summative demands desired by the university (performance). In addition, the two dimensions (individual/public and reflection/performance) define the boundaries of professional development for university faculty in the three areas of scholarship as well as other professional competencies.

We believe this model offers faculty developers a framework for designing thoughtful practice to aid faculty in meeting the wide range of internal and external demands that confront higher education institutions. Awareness of the four quadrants and a need to attend to each in a deliberate fashion holds promise for making our professional development efforts more effective, long lasting, and meaningful. If professional developers desire programs that facilitate transformation, it seems necessary to do so with more sophisticated and powerful models of personal and social change. The proposed model recognizes the dialectic between individual and public within an organization; it acknowledges the dynamic between reflection and performance that is crucial to real learning.

The flexibility of this model empowers developers to consider the philosophical perspective they bring to its use, the needs of audience members, and the emphases appropriate for designing experiences that promote holistic growth given specific learning goals. Although further exploration is needed to empirically ground our proposed model, we hope this framework contributes to an important and expanding discourse on transformative learning experiences for faculty. We invite readers to join us in examining this model for its applicability in various contexts-from the small-scale process of one-on-one faculty consultation to the large-scale process of shaping and implementing a systematic, connected series of programs. 


\section{REFERENCES}

Astin, A. W., \& Colleagues. (2001, July). Toward a theory of institutional transformation in higher education. Paper presented at the annual meeting of the AAC\&U Institure on Campus Leadership for Sustainable Innovation, Leesburg, VA.

Cranton, P. (1994). Understanding and promoting transformative learning: A guide for educators of adults. San Francisco, CA: Jossey-Bass.

Cranton, P. (1996). Professional development as transformative learning: New perspectives for teachers of adults. San Francisco, CA: Jossey-Bass.

Farquhar, R. (2001). Faculty renewal and institutional revitalization in Canadian universities. Change, 33(4), 12-20.

Green, M. (2002). Joining the world: The challenge to internationalizing undergraduate education. Change, 34(3), 12-21.

Lovett, C. (2002). Cracks in the bedrock: Can U. S. higher education remain number one? Change, 34(2), 10-15.

Mezirow, J. (1991). Transformative dimensions of adult learning. San Francisco, CA: Jossey-Bass.

Mezirow, J. (2000). Learning to think like an adult: Core concepts of transformation theory. In J. Mezirow \& Associares (Eds.), Learning as transformation: Critical perspectives on a theory in progress (pp. 3-33). San Francisco, CA: Jossey-Bass

Newman, F., \& Couturier, L. (2001). The new competitive arena: Market forces invade the academy. Change, 33(5), 10-17.

Senge, P. (1990). The fifth discipline: The art and practice of a learning organization. New York, NY: Doubleday.

Swail, W. (2002). Higher education and the new demographics: Questions for policy. Change, 34(4), 14-23.

Wilber, K. (2000). The four corners of the known universe. In K. Wilber (Ed.), The collected works of Ken Wilber (Vol. 8, pp. 135-148). Boston, MA: Shambhala. 


\section{Contact:}

David J. Langley

Center for Teaching and Learning

Indiana State University

127 Dreiser Hall

Terre Haute, IN 47809

Voice (812) 237-4452

Fax (812) 237-3053

Email dlangley@indstate.edu

Terence W. O'Connor

School of Education

The College of New Jersey

2000 Pennington Road

Ewing, NJ 08628

Voice (609) 771-2100

Email oconnor@tcnj.edu

Michele M. Welkener

Center for Teaching and Learning

Indiana State University

127 Dreiser Hall

Terre Haute, IN 47809

Voice (812) 237-3057

Fax (812) 237-3053

Email mwelkener@indstate.edu

David J. Langley is Interim Director of the Center for Teaching and Learning and Associate Professor in the Department of Physical Education at Indiana State University. His work at the center focuses on generating and implementing various campus-wide initiatives on faculty development. His scholarly interests in higher education involve transformative learning, models for professional development, and assessment practices.

Terence W. O'Connor is Dean of the School of Education and Professor in the Department of Educational Administration and Sccondary Education at The College of New Jersey. He was awarded a three-year FIPSE grant in 2000 on promoting strategic teaching to enhance the academic competencies of students in transition courses. He has been a frequent presenter at numerous conferences in higher education and is currently completing a book on patterns and routines underlying successful teaching.

Michele M. Welkener serves as the Assistant Director of the Center for Teaching and Learning at Indiana State University, where she designs and implements professional devclopment programming for teaching assistants and faculty. Creativity and college student development are at the center of her interdisciplinary scholarship. 